\author{
UNIVERSIDADE DE SÃO PAULO \\ INSTITUTO DE ESTUDOS BRASILEIROS \\ PROGRAMA DE PÓS-GRADUAÇÃO \\ CULTURAS E IDENTIDADES BRASILEIRAS
}

\title{
Casa de Francisca: experiências e experimentações na menor casa de shows de São Paulo
}

MARINA VAZ MOREIRA

Orientador: Prof ${ }^{\mathrm{o}}$. Dr ${ }^{\mathrm{o}}$. Walter Garcia

São Paulo

2019

MOREIRA, Marina Vaz. Casa de Francisca: experiências e experimentações na menor casa de shows de São Paulo. 2019. 135 f. Dissertação (Mestrado em Culturas e Identidades Brasileiras) - Instituto de Estudos Brasileiros, Universidade de São Paulo, São Paulo, 2019.

Sob perspectiva interdisciplinar e em formato de grande reportagem, esta dissertação aborda a história da Casa de Francisca, espaço de shows com capacidade para cerca de 40 pessoas, que funcionou em um sobrado do bairro do Jardim Paulista, na cidade de São Paulo, entre os anos de 2007 e 2016. A partir de entrevistas com seus fundadores e com artistas, buscou-se identificar as relações interpessoais e as experimentações musicais que foram, muitas vezes, viabilizadas e/ou catalisadas pelas reduzidas dimensões físicas do local. Quanto à programação, a Casa acolhia diferentes gerações de músicos e cantores, entre eles, alguns nomes cujos depoimentos foram colhidos para este trabalho: Arrigo Barnabé; Benjamim Taubkin; Criolo; Juçara Marçal; Kiko Dinucci; Ná Ozzetti; Rodrigo Campos; Romulo Fróes; Siba; e Zé Miguel Wisnik. Para exemplificar parte da produção artística difundida ali, utilizando recursos ligados à 
teoria e crítica literária, também foi feita a análise de algumas canções apresentadas no local antes mesmo de ganharem registros fonográficos ou audiovisuais.

Palavras-chave: Música popular. Casa de show. São Paulo. Cultura brasileira. Espaços culturais. Canção.

\begin{abstract}
MOREIRA, Marina Vaz. Casa de Francisca: experiences and experimentations at the smallest music hall of São Paulo. 2019. 135 f. Dissertação (Mestrado em Culturas e Identidades Brasileiras) - Instituto de Estudos Brasileiros, Universidade de São Paulo, São Paulo, 2019.
\end{abstract}

With an interdisciplinary approach and a reportage format, this dissertation examines the history of Casa de Francisca, a music hall with capacity for approximately 40 people, which occupied, from 2007 to 2016, a small house located in the neighborhood of Jardim Paulista, in the Brazilian city of São Paulo. Based on interviews with its founders and artists, this research proposes to identify interpersonal relationships and musical experimentations, that were made possible and/or catalyzed by the reduced space of the music hall. In its musical programming, Casa de Francisca has welcomed different generations of musicians and singers, among them, some names that have been interviewed for this dissertation: Arrigo Barnabé; Benjamin Taubkin; Criolo; Juçara Marçal; Kiko Dinucci; Ná Ozzetti; Rodrigo Campos; Romulo Fróes; Siba; and Zé Miguel Wisnik. In order to exemplify part of the artistic production disseminated there, using resources of literary criticism and theory, an analysis was made of some songs that were performed in the music hall even before their phonographic or audiovisual releases.

Keywords: Popular music. Music hall. São Paulo. Brazilian culture. Cultural spaces. Song. 


\section{Apresentação}

Tendo em vista uma perspectiva multidisciplinar, esta dissertação é composta por uma grande reportagem sobre a história da Casa de Francisca - casa de shows cuja primeira sede funcionou, entre 2007 e 2016, em um sobrado no bairro do Jardim Paulista, em São Paulo -, a partir de depoimentos de fundadores, funcionários e também de artistas que integraram sua programação. Desde o início, a intenção, para além do registro de acontecimentos ligados a esse pequeno espaço cultural, foi identificar, como o próprio título do trabalho sugere, as experiências interpessoais e musicais ocorridas nele, assim como as experimentações artísticas que ele possibilitou.

O que unia os artistas que se apresentavam na Casa de Francisca? Que tipo de vivência aquele sobrado, que recebia, a cada noite, pouco mais de 40 pessoas, possibilitava para músicos e plateia, antes, durante e depois dos shows? Em que medida a estrutura física da Casa - com um contato mais íntimo entre artista e público influenciou os trabalhos exibidos ali? Essas são algumas perguntas que esta pesquisa se propôs a esclarecer, sem, contudo, pretender esgota-las ou responde-las em sua totalidade.

A metodologia utilizada incluiu bibliografia multidisciplinar; entrevistas; pesquisas em veículos de comunicação e redes sociais; pesquisa iconográfica a partir de mais de 1.100 imagens pertencentes ao acervos de Rubens Amatto, cofundador da Casa, e da fotógrafa Katia Kuwabara; levantamento de apresentações feitas por diversos artistas, com base em planilha que registrou a venda de ingressos de cerca de 1.500 shows, entre maio de 2010 e dezembro de 2016; além da análise de algumas performances e canções apresentadas ali.

No caso das entrevistas, elas partiram de perguntas específicas para cada artista, em conversas realizadas, sempre que possível, pessoalmente. Desde o início da pesquisa, em agosto de 2017, foram colhidos depoimentos de 13 entrevistados ligados à história da Casa, totalizando cerca de 21 horas de gravação.

Os critérios para a escolha desses artistas levaram em conta elementos como: a longevidade da relação deles com a Casa de Francisca (a exemplo de Kiko Dinucci); a regularidade de shows feitos durante o período analisado (caso de Juçara Marçal e Romulo Fróes); a representatividade do artista dentro de determinadas formas de música que tiveram espaço na casa (o pernambucano Siba, ligado a uma sonoridade que 
reverencia ritmos tradicionais brasileiros; o pianista Benjamim Taubkin, nome da música instrumental contemporânea; além do cantor e compositor Criolo, que tem estreita relação com rap); e também o pertencimento a gerações anteriores aos anos 2000, "resgatadas" e enaltecidas na programação da Casa (como Arrigo Barnabé e Ná Ozzetti, ligados à chamada Vanguarda Paulista, que marcou os anos 1980).

Assim, foram colhidos os seguintes depoimentos:

- Rubens Amatto, cofundador e atual proprietário da Casa (a primeira entrevista foi realizada, pessoalmente, no dia 21 de setembro de 2017, no Palacete Tereza Toledo Lara, na Sé, atual sede da Casa de Francisca; a segunda, em 28 de setembro de 2017, em um café nas proximidades da Avenida Paulista; a terceira e a quarta entrevistas, voltadas, principalmente, ao acervo de fotografias da Casa, ocorreram nos dias $1^{\circ}$ de fevereiro e 13 de maio de 2019, também na atual sede);

- Rodrigo Luz, cofundador da Casa (por telefone, no dia 19 de outubro de 2017);

- Arrigo Barnabé, músico, compositor e cantor (pessoalmente, no dia 27 de outubro de 2017, no Palacete Tereza Toledo Lara);

- Romulo Fróes, músico, compositor e cantor (pessoalmente, no dia 31 de outubro de 2017, no apartamento onde ele mora, no bairro de Santa Cecília);

- Ná Ozzetti, cantora (pessoalmente, no dia 6 de novembro de 2017, no apartamento da mãe da artista, na região da Água Branca);

- Rodrigo Campos, músico, compositor e cantor (pessoalmente, no dia 13 de novembro de 2017, em um café no bairro de Pinheiros);

- Kiko Dinucci, compositor, músico e cantor (pessoalmente, no dia 23 de novembro de 2017, no café do Sesc 24 de Maio, na região da República);

- Juçara Marçal, cantora (pessoalmente, no dia 8 de dezembro de 2017, em um café localizado na Vila Madalena);

- José Miguel Wisnik, músico, compositor, ensaísta e professor (por e-mail, com respostas enviadas no dia 3 de agosto de 2018);

- Siba, músico, cantor e compositor (por telefone, no dia 16 de janeiro de 2019);

- Benjamim Taubkin, pianista, compositor e arranjador (por telefone, no dia 17 de janeiro de 2019);

- Criolo, rapper, cantor e compositor (por telefone, no dia 23 de janeiro de 2019); 
- Fernanda Pereira, que trabalhou, por muitos anos, como responsável administrativa da Casa de Francisca (pessoalmente, em sua casa no Planalto Paulista, no dia 12 de fevereiro de 2019).

A dissertação está estruturada em sete capítulos. "A casa" e "O início" apresentam, respectivamente, uma breve ambientação da Casa de Francisca e as motivações e ações iniciais que culminaram em sua abertura, a partir das ideias e da amizade de seus dois fundadores, Rodrigo Luz e Rubens Amatto. "A cidade" busca contextualizar, cultural e urbanisticamente, a São Paulo da primeira década dos anos 2000 , incluindo outras casas de show surgidas ou mantidas no período. "A porta aberta" revela os primeiros shows abertos ao público, após a longa reforma do imóvel, que se estendeu por quase um ano.

"As experiências, as experimentações" traça um panorama das relações pessoais e artísticas que se desenvolveram dentro da Casa de Francisca, assim como os resultados estético-musicais dessas interações, incluindo projetos autorais e discos gestados ali. Para exemplificar um pouco da produção musical abarcada pela pequena casa de shows, relatos e impressões dos entrevistados são entremeados com a análise de três canções e suas performances, apresentadas ali antes mesmo de ganharem registros sonoros e/ou audiovisuais: "Ciranda do aborto", composição de Kiko Dinucci, gravada por Juçara Marçal em seu disco Encarnado (2014); “Como um raio", parceria de Romulo Fróes e Nuno Ramos, que integra o disco Barulho Feio (2014), de Romulo; e "Nervos de Aço", de Lupicínio Rodrigues, que ganhou versão de Arrigo Barnabé durante a temporada do show dedicado à obra do compositor, Caixa de Ódio, gravado, posteriormente, em DVD. No caso das letras de canções, a análise partiu de estudos ligados à tradição de teoria e crítica literária que tem em Antonio Candido seu principal nome.

Já o capítulo "Os consertos, os concertos" é dedicado ao festival colaborativo criado, originalmente, para levantar fundos para a conclusão de uma reforma, que deixou a casa de shows fechada por alguns meses, em 2012, e que, nos anos seguintes, reuniu dezenas de artistas ligados à Francisca em espaços como o Teatro Oficina e o Teatro Municipal de São Paulo. Por fim, "O palacete, um balanço" aborda o fechamento da antiga sede, no Jardim Paulista; a mudança para um palacete restaurado, no centro histórico de São Paulo; e os novos rumos seguidos pela Casa. 


\section{Referências bibliográficas}

ARAÚJO, Luís André Bezerra de. Sérgio Sampaio e a Paródia Tropicalista em Eu Quero É Botar meu Bloco na Rua. Dissertação (Mestrado em Letras) - Universidade Federal da Paraíba, João Pessoa, 2009.

ANDRADE, Mário de. Dicionário Musical Brasileiro. Belo Horizonte: Editora Itatiaia, 1999.

BRITTO, Paulo Henriques. Eu Quero É Botar Meu Bloco na Rua, de Sérgio Sampaio. Rio de Janeiro: Língua Geral, 2009.

BUITONI, Dulcilia Schroeder. De volta ao quintal mágico: a educação infantil na TeArte. São Paulo: Editora Ágora, 2006.

CALDEIRA, Teresa Pires. Cidade dos Muros. Crime, segregação e cidadania em São Paulo. São Paulo: Edusp, 2000.

CANDIDO, Antonio. O Estudo Analítico do Poema. $4^{\mathrm{a}}$ edição. São Paulo: Associação Editorial Humanitas, 2004.

CHEVALIER, Jean. Dicionário de Símbolos. Rio de Janeiro: Editora José Olympio, 2007.

DINIZ, S.; ÁVILA, D. ““A canção pode morrer, mas eu não vou morrer, não...’: uma entrevista com Kiko Dinucci”. Música Popular em Revista, Campinas, ano 5, v. 2, p. 176-199, jan.-jul. 2018.

FENERICK, José Adriano. Façanha às Próprias Custas: A Produção Musical da Vanguarda Paulista (1979-2000). São Paulo: Annablume Editora, 2007.

FERNANDES, Sílvia. “Teatro-Cidade", Revista d'Art, Divisão de Pesquisas do Centro Cultural São Paulo, São Paulo, 2003.

FISCHER, Stela. Processo colaborativo e experiências de companhias teatrais brasileiras. São Paulo: Hucitec, 2010.

GALlETTA, Thiago Pires. Cena musical independente paulistana-início dos anos 2010: a "música brasileira" depois da internet. Dissertação (mestrado) - Instituto de Filosofia e Ciências Humanas, Universidade Estadual de Campinas, 2013.

GARCIA, Walter. "Notas Sobre o Disco Encarnado, de Juçara Marçal (2014)". Revista USP, $\mathrm{n}^{\circ} 111,2016$, p. 59-68. ."Clara Crocodilo' e 'Nego Dito': Dois Perigosos Marginais?”.

Antíteses, Londrina, vol. 8, nº 15, jul./dez. 2015. 
LEITE, Carlos Augusto Bonifácio, "Sobre o peso de si e maestrias: uma análise de parte da cena atual da canção popular brasileira". Revista do Instituto de Estudos Brasileiros, $n^{\circ}$ 59. São Paulo, dez. 2014.

MELO, Zuza Homem de. Copacabana: a trajetória do samba-canção (1929-1958). São Paulo: Editora 34/Edições Sesc, 2017.

MACHADO, Regina. A voz na canção popular brasileira: um estudo sobre a Vanguarda Paulista. São Paulo: Ateliê Editorial, 2011.

MENEZES, Adélia Bezerra de. Figuras do Feminino na Canção de Chico Buarque. São Paulo: Ateliê Editorial, 2000.

São Paulo: Ateliê Editorial, 2002. Desenho mágico: poesia e política em Chico Buarque.

NAZARIO, Luiz. "O universo de Clara Crocodilo". Revista do Instituto de Estudos Brasileiros. São Paulo, no 59, p. 413-418, dez. 2014.

NEGREIROS, Eliete Eça. Ensaiando a Canção, Paulinho da Viola. Dissertação (Mestrado em Filosofia) - Faculdade de Filosofia, Letras e Ciências Humanas, Universidade de São Paulo, São Paulo, 2012.

OLIVEIRA, Laerte Fernandes de. Em um Porão de São Paulo... O Lira Paulistana e a Produção Alternativa. São Paulo: Annablume Editora, 2002.

PEREIRA, Fernanda Keli. A música, linguagem tradutora: a Nota Azul e outros matizes. Dissertação (Mestrado em Educação) - Faculdade de Educação, Universidade de São Paulo, São Paulo, 2018.

PICCHIA, Paulo Menotti del. Por que eles ainda gravam? Discos e artistas em ação. Dissertação (Mestrado em Antropologia Social) - Faculdade de Filosofia, Letras e Ciências Humanas, Universidade de São Paulo, São Paulo, 2013.

ROSENFELD, Anatol. “A Teoria dos Gêneros”. O Teatro Épico. São Paulo: Perspectiva, 1985.

TELESI, Sílvia F. Grupos teatrais: anos 70. Campinas: Editora da Unicamp, 2000. . "Teatro-Cidade". Revista d'Art, Divisão de Pesquisas do Centro Cultural São Paulo, São Paulo, 2003.

VILAÇA, Túlio. "Ciranda do Aborto". Revista Polivox, maio/2014.

VILLACA, Flávio. "São Paulo: segregação urbana e desigualdade". Estudos Avançados, São Paulo, v. 25, n. 71, p. 37-58, abr. 2011. 


\section{Jornal, revista e internet}

SEM AUTOR. "Veja a programação dos blocos de rua do carnaval 2019 em São Paulo", G1, 18/12/2018. Disponível em: https:/g1.globo.com/sp/saopaulo/carnaval/2019/noticia/2018/12/18/veja-a-programacao-dos-blocos-de-rua-docarnaval-2019-em-sao-paulo.ghtml. Acesso em: 13/08/2019.

SEM AUTOR. "Ícone do Baixo Augusta, Studio SP fecha a porta depois de oito anos", Folha de S. Paulo, 11/04/2013. Disponível em: https://www1.folha.uol.com.br/ilustrada/ 2013/04/1261134-icone-do-baixo-augustastudio-sp-fecha-as-portas-depois-de-oito-anos.shtml. Acesso em: 19/07/2019.

SEM AUTOR. "Serralheria | Série "Casas de show", Observatório Itaú Cultural, 11/06/2015. Disponível em: https://www.itaucultural.org.br/serralheria-serie-casas-deshow. Acesso em: 29/07/2019.

SEM AUTOR. "Serralheria | Série "Casas de show", Observatório Itaú Cultural, 11/06/2015. Disponível em: https://www.itaucultural.org.br/serralheria-serie-casas-deshow. Acesso em: 29/07/2019.

ALMEIDA, Valdir. "Caso Damião: $1^{\mathrm{a}}$ condenação do Brasil na OEA completa 10 anos", G1, 30/08/2016. Disponível: http://g1.globo.com/ceara/noticia/2016/08/casodamiao-1-condenacao-do-brasil-na-oea-completa-10-anos.html. Acesso em: 25/06/2019.

AMORIM, Felipe; PRAZERES, Leandro. "Oposição entrega pedido de impeachment com base em novas pedaladas". UOL, 21/10/2015. Disponível em: https://noticias.uol.com.br/politica/ultimas-noticias/2015/10/21/pedido-deimpeachment-de-dilma-e-apresentado-na-camara.htm. Acesso em 11/11/2019.

ANTUNES, Pedro. "Criolo mostra rap com nova embalagem". O Estado de S. Paulo, 01/05/2011. Disponível em: https://www.estadao.com.br/blogs/jt-variedades/criolomostra-rap-com-nova-embalagem/. Acesso em: 27/06/ 2019.

AZEVEDO, Victoria. "Restaurante em Pinheiros, Bona abre espaço para shows com clima intimista", Guia Folha, Folha de S.Paulo, 10/11/2017. Disponível em: https://guia.folha.uol.com.br/shows/2017/11/restaurante-em-pinheiros-bona-abreespaco-para-shows-com-clima-intimista.shtml. Acesso em: 17/06/2019.

BERNARDO, Leonam. "Projeto do Studio SP, Cedo e Sentado muda-se para o Grazie a Dio", Veja São Paulo, 27/04/2013. Disponível em:

https://vejasp.abril.com.br/blog/passagem-de-som/projeto-do-studio-sp-cedo-e-sentadomuda-se-para-o-grazie-a-dio/. Acesso em: 19/07/2019. 
BRASIL, Ubiratan. "Os oito pilares da gestão de Alê Youssef para a cultura", O Estado de S. Paulo, 01/02/2019. Disponível em:

https://cultura.estadao.com.br/noticias/geral,os-oito-pilares-da-gestao-de-ale-youssefpara-a-cultura,70002704064. Acesso em: 29/07/2019.

CONTER, Adriano. "Studio SP inaugura filial na Vila Madalena", Veja São Paulo, 22/11/2011. Disponível em: https://vejasp.abril.com.br/cidades/studio-sp-inaugurafilial-na-vila-madalena/. Acesso em: 19/07/2019.

D’AMBROSIO, Tiago Barbosa; FRACASSI, Marcel. "Puxadinho da Praça | Série 'Casas de show'”, Observatório Itaú Cultural, 08/07/2015. Disponível:

www.itaucultural.org.br/puxadinho-da-praca-serie-casas-de-show. Acesso em: 29/07/2019.

FRACASSI, Marcel. "As pequenas casas de música na dinâmica cultural de São Paulo", Observatório Itaú Cultural, 05/01/2016. Disponível em:

www.itaucultural.org.br/cidades-e-sua-dinamica-cultural-serie-casas-de-show. Acesso em: 28/10/2019.

FABRINI, Fábio; VILLAVERDE, João; CARAM, Bernardo. "Em decisão unânime, TCU rejeita contas do governo Dilma em 2014”, O Estado de S. Paulo, 07/10/2015. Disponível em: https://politica.estadao.com.br/noticias/geral,tcu-rejeita-contas-dedilma-por-pedaladas-fiscais, 1776349. Acesso em: 11/11/2019.

FRACASSI, Marcel. "As pequenas casas de música na dinâmica cultural de São Paulo", Observatório Itaú Cultural, 05/01/2016. Disponível em:

www.itaucultural.org.br/cidades-e-sua-dinamica-cultural-serie-casas-de-show. Acesso em: 28/10/2019.

LOPES, Maria Amélia Rocha. "Aqui está surgindo a nova música de São Paulo", Jornal da Tarde, 10/07/1982.

MARIA, Julio.”Vila Madalena ganha nova casa de shows". O Estado de S. Paulo, 09/03/2017. Disponível em: https://cultura.estadao.com.br/noticias/musica,vilamadalena-ganha-nova-casa-de-shows,70001691919. Acesso em: 17/06/2019.

NOGUEIRA, Amanda; AZEVEDO, Victoria. "Minúscula Casa de Francisca reabre pequena no histórico Palacete Teresa", Folha de S.Paulo, 10/02/2017. Disponível em: https://www1.folha.uol.com.br/ilustrada/2017/02/1857553-minuscula-casa-defrancisca-reabre-pequena-no-historico-palacete-tereza.shtml. Acesso em: 11/11/2019. 
PASCOAL, Carol. “Ícone dos anos 80, Arrigo Barnabé lança DVD”, Veja São Paulo, 01/06/2017. Disponível em: https://vejasp.abril.com.br/cidades/icone-nos-anos-80arrigo-barnabe-lanca-dvd/. Acesso em: 22/08/2019.

PUTINI, Rafaela; TITO, Fábio. "Virada Cultural 2019 tem público recorde, diz prefeito de São Paulo”, G1, 19/05/2019. Disponível em: https://g1.globo.com/sp/sao-

paulo/noticia/2019/05/19/virada-cultural-2019-tem-publico-recorde-diz-prefeito-de-saopaulo.ghtml. Acesso em: 13/08/2019.

RIBEIRO, Bruno. "Vistoria do Corpo de Bombeiros vê risco em eventos no Minhocão", O Estado de S. Paulo, 11/07/2015. Disponível em: https://saopaulo.estadao.com.br/noticias/geral,bombeiros-veem-risco-em-eventos-nominhocao, 1723088. Acesso em: 11/11/2019.

SOARES, Ana Carolina. "Haddad perde principal subprefeito", Veja São Paulo, 27/02/2017. Disponível em: https://vejasp.abril.com.br/blog/terraco-paulistano/haddadperde-principal-subprefeito/. Acesso em: 17/06/2019.

URIBE, Gustavo; LIMA, Daniela; LIMA, Galeno. "Manifestação contra Dilma reúne 2.500 pessoas em São Paulo”, Folha de S.Paulo, 01/11/2014. Disponível em: https://www1.folha.uol.com.br/poder/2014/11/1542047-ato-em-sao-paulo-pedeimpeachment-de-dilma-e-intervencao-militar.shtml. Acesso em 12/11/2019.

VICTOR, Fabio; SEVERINO, Thea. "Palacete histórico no centro de SP abrigará nova Casa de Francisca”. Folha de S. Paulo, 14/08/2015. Disponível em:

https://m.folha.uol.com.br/ilustrada/2015/08/1668439-palacete-historico-no-centro-desp-abrigara-nova-casa-de-francisca.shtml. Acesso em: 11/11/2019.

WISNIK, José Miguel. "Menor e Enorme”, O Globo, 08/11/2014.

\section{Referências audiovisuais}

BARNABÉ, Arrigo. Clara Crocodilo. Thanx God Records, 1980.

BARNABÉ, Arrigo. Caixa de Ódio (DVD). Canal Brasil, 2011

CRIOLO, Nó na Orelha. Oloko Records, 2011.

FRÓES, Romulo. Barulho Feio. YB Music, 2014. 
MARÇAL, Juçara; DINUCCI, Kiko. Padê. Cooperativa de Música, 2007.

MARÇAL, Juçara. Encarnado, Independente, 2014.

METÁ METÁ. Metá Metá. Desmonta/Circus, 2011.

PASSO TORTO, Passo torto. YB Music, 2011.

VELOSO, Caetano. Caetano Veloso. Philips, 1969.

VIOLA, Paulinho da. Nervos de aço. Odeon, 1973. 